\title{
EXPERIMENTAL AND ANALYTICAL INVESTIGATION ON EFFECT OF STATOR WINDING TYPE TO EQUIVALENT CIRCUIT PARAMETERS OF INDUCTION MOTORS
}

\author{
Fevzi Kentli' ${ }^{1}$, Aykut Kentli ${ }^{2}$
}

\begin{abstract}
Because of development in technology, the design of electrical machinery is changing. Induction motors, mostly used as electrical equipment, have developed over the years. One analytically studied area is the stator winding. Generally, each manufacturer uses techniques that directly affect the power of motors and thus, motor efficiency. In this study, the effects of three different stator winding types on motor parameters are investigated. Experiments are performed under no-load, load, and locked rotor conditions. Terminal voltage, power per phase, and phase current values are measured. Power and certain parameters are calculated using an equivalent circuit model. Lastly, a comparison of the results is provided.
\end{abstract}

UDC Classification: 621.3 DOI: http://dx.doi.org/10.12955/cbup.v4.859

Keywords: Stator winding, Power, Equivalent Circuit Parameters.

\section{Introduction}

Increasing the speed of processing is the main goal of today's industry. Each technological development regarding electrical motors has brought increase in speed as well as increase in production and efficiency, and with it, reduction in working time and ease in working conditions. Therefore, various types of electrical motors have been widely used in industry over time. Mainly 3phase induction motors (slip-ring, cage, and blocked rotor types) are used today and among these motors, cage induction types are the most common.

Cage induction motors have several advantages, including a speed rate that remains largely unchanged in conditions that require increased use during operation. Also, rotors can be manufactured by diecasting in small and middle power applications that allow rapid production. These are preferred as they are reliable, require less maintenance, and display high operational safety. Producing low torque and a high current at the start of operation is their disadvantage.

To identify the parameter values of induction motors, generally equivalent circuit models of the motors are established, followed by experiments under different conditions (no-load and locked rotor) to measure parameters. Lastly, using equivalent model equations identifies the unmeasured parameters.

Several researchers have studied the identification of induction motor parameters. Gastli (1999) used single-phase tests with variable frequency power supply. Phumiphak and Chat-Uthai (2002) used blocked rotor tests only and then Genetic Algorithm (GA) to find the equivalent circuit parameters that minimized cost. Kral, Haumer, and Grabner (2010) calculated the parameters at nominal operating points and compared the results of several motors for different power ranges. Boglietti, Cavagnino, and Lazzari (2011) proposed and analyzed certain methodologies to calculate phase resistance and leakage inductances. Boglietti, Bojoi, Cavagnino, Guglielmi, and Miotto (2012) performed experimental tests on high speed induction motors and used results of a Finite Element Method (FEM) analysis to calculate parameters. Ling, Zhou, Guo, \& Zhang (2014) used FEM analysis in calculations and compared the results with traditional analytical solutions.

This study identifies the values of parameters that are unmeasured for core loss resistance and magnetized resistance in the exact equivalent circuit of an induction motor. The study advances the former study of the authors (Kentli \& Temiz, 1999). In addition, the effect of stator winding types on parameters is investigated.

\section{Stator Windings in Three Phase Induction Motor}

Induction motors can be produced with one, three, or more phases of windings in stator. These windings can be established in as one-layer or two-layer fractional and series windings. The stator

\footnotetext{
${ }^{1}$ Fevzi Kentli, Marmara Universiy, Technology Faculty, Istanbul, Turkey, fkentli@marmara.edu.tr

2 Aykut Kentli, Marmara University, Engineering Faculty, Istanbul, Turkey, akentli@marmara.edu.tr
} 
winding of induction motors, has a wide spread of usage in industry and is produced in several types related to its manufacturer. The stator winding structure affects several motor parameters, such as efficiency, power, overload, heating, magnetic noise, current's amplitude, and shape. Change in the winding structure enables change in the parameters of the motors. For example, power factor is an important parameter. As the winding type affects power factor, there may be a requirement to compensate reactive power for low values. Moreover, efficiency has a direct relationship with power.

Sivaraju and Chandrasekaran (2014) designed an optimal induction motor with multi-flux stator winding using GA algorithm and compared the results with the conventional design for a $2.2-\mathrm{kW}$ three-phase squirrel cage induction motor. Saravanan, Azarudeen, \& Selvakumar (2012) improved efficiency of an induction motor using modified stator winding and validated their results experimentally. Buksnaitis (2010) performed a theoretical analysis of electromagnetic efficiencies of two types of three-phase windings and compared their results with experimental ones. Zhang, Huang, Dong, Guo, \& Zhou (2014) dealt with stator winding designs of induction motors for high efficiency. Hadziselimovic, Marcic, Stumberger, \& Zagradisnik (2011) investigated the influence of concentric single layer winding, concentric double layer winding, and fractional concentric winding on the efficiency of an induction motor. This study concerns three types of windings: single-layer two-floor, single-layer three-floor, and a double layer, as shown in Figure 1.

\section{Identification of Equivalent Circuit Parameters}

Induction motor parameters need definition to have optimum efficiency and control. Usually, the manufacturer provides values for several parameters (e.g., nominal output power, nominal frequency, nominal voltage, nominal speed, efficiency, and nominal power), while the rest need experimental identification. Each experiment takes time and cost, and not all parameters can be defined correctly. Thus, modeling and analytical analysis of the motor are required. An equivalent circuit of induction motor is used for this purpose as shown in Figure 2.

Figure 1: Winding types: (a) single-layer two-floor, (b) single-layer three-floor, (c) double layer

(a)

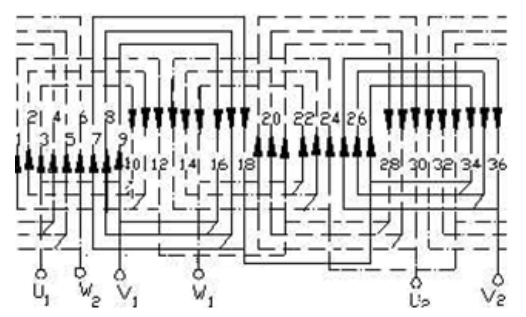

(b)

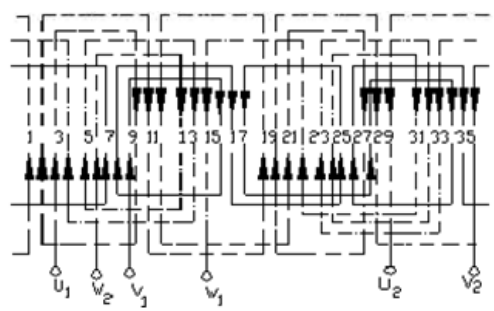

(c)

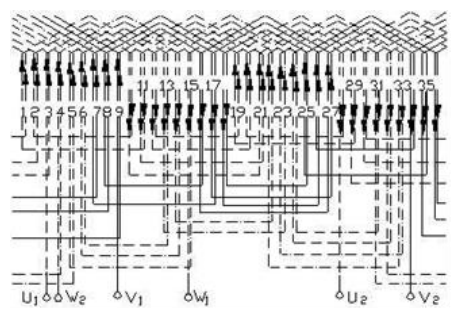

Source: Kentli and Temiz (1999)

A machine will rotate at almost a synchronous speed with no load, and produce a slip of close to zero. The small power to the machine is due to core losses, friction, and winding losses. A "no load" test is represented by an equivalent circuit, although this circuit is only an approximate. In the following sections, iron loss resistance $\left(\mathrm{R}_{\mathrm{fe}}\right)$ and magnetizing reactance $\left(\mathrm{X}_{\mathrm{m}}\right)$ values are investigated using the actual equivalent circuit. The inverse of parallel impedance is written, as in Equation 1. Here, $\mathrm{R}_{\mathrm{fe}}$ and $X_{m}$ values are unmeasured parameters.

$$
\mathrm{I}_{1} \angle-\varphi=\mathrm{U}_{1} \angle 0^{\circ} / \mathrm{Z}_{1} \angle \varphi
$$

where $\mathrm{U}_{1}=$ Terminal voltage, $\mathrm{Z}_{\mathrm{t}}=$ Total impedance, $\varphi=$ Angle between $\mathrm{U}_{1}$ and $\mathrm{I}_{1}$

$$
\frac{1}{Z_{p}}=\frac{1}{R_{f e}}+\frac{1}{j X_{m}}+\frac{1}{R_{2}^{\prime} / s+j X_{2 \sigma}^{\prime}}
$$

Therefore, parallel impedance could be calculated as: 


$$
Z_{p}=\frac{R_{f e} j X_{m}\left(R_{2}^{\prime} / s+j X_{2 \sigma}^{\prime}\right)}{A}
$$

where $A=\left\lfloor j X_{m}\left(R_{2}^{\prime} / s+j X_{2 \sigma}^{\prime}\right)\right]+\left[R_{f e}\left(R_{2}^{\prime} / s+j X_{2 \sigma}^{\prime}\right)\right\rfloor+R_{f e} j X_{m}$

Figure 2: Schematic view of equivalent circuit model

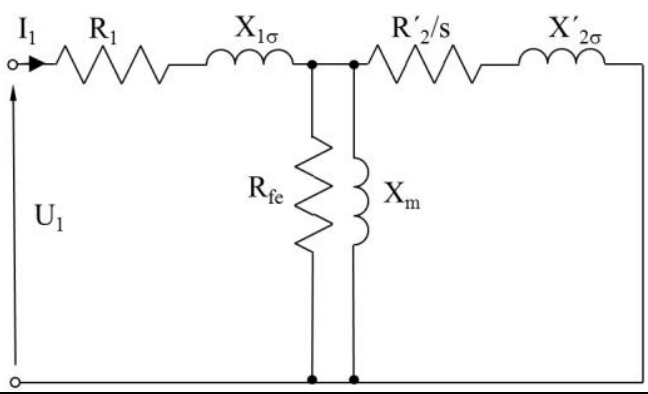

$I_{1}=$ Phase current, $R_{1}=$ Stator winding effective ohmic resistance, $X_{1 \sigma}=$ Stator leakage flux reactance, $\mathrm{s}=\mathrm{Slip}, \mathrm{R}_{2}{ }_{2}=$ Rotor effective ohmic resistance referred to the stator, $\mathrm{X}_{2 \sigma}{ }_{2 \sigma}=$ Rotor leakage flux reactance referred to the stator, $\mathrm{R}_{\mathrm{fe}}=$ Iron loss resistance, $\mathrm{X}_{\mathrm{m}}=$ Magnetizing reactance, $\mathrm{U}_{1}=$ Terminal voltage. All these parameters are per phase

Source: Author

Equivalent impedance value is the sum of parallel impedance and reactance, as follows:

$$
Z_{t}=Z_{1}+Z_{p}
$$

where $Z_{1}=R_{1}+j X_{1 \sigma}$

Equivalent impedance formula in terms of no measured parameters becomes

$$
\begin{aligned}
& Z_{t}=R_{t}+j X_{t} \\
& R_{t}=\frac{R_{1} B-X_{2 \sigma}^{\prime} R_{2}^{\prime} R_{f e}^{2} X_{m} / s+X_{2 \sigma}^{\prime 2} X_{m}^{2} R_{f e}}{B} \\
& X_{t}=\frac{R_{2}^{\prime} R_{f e} X_{m} / s+X_{2 \sigma}^{\prime 2} R_{f e}^{2} X_{m}+R_{2}^{\prime} X_{2 \sigma}^{\prime} R_{f e} X_{m}^{2} / s+X_{2 \sigma}^{\prime} R_{f e}^{2} X_{m}^{2}+X_{1 \sigma} B}{B}
\end{aligned}
$$

where

$$
B=\left(R_{2}^{\prime} R_{f e} / s-X_{2 \sigma^{\prime}}^{\prime} X_{m}\right)^{2}+\left(X_{2 \sigma}^{\prime} R_{f e}+R_{2}^{\prime} X_{m} / s+R_{f e} X_{m}\right)^{2}
$$

Power factor was obtained experimentally as being equal to $\operatorname{Cos} \varphi$, where $\operatorname{tg} \varphi=X_{t} \div R_{t}$

Using Matlab code, different $\mathrm{R}_{\mathrm{fe}}$ and $\mathrm{X}_{\mathrm{m}}$ values were tested and the values providing this equality were obtained. The results section gives the calculated values. Measured dc resistance values are multiplied with a factor which is equal to 1.1 to convert into alternating current values in all calculations.

\section{Experimental Setup}

In this study, three AGM 90S4 type cage induction motors with the same construction were used. Stator comprised 36 semi-closed and trapezoidal slots. Stator windings of induction motors used in the experiments were different from each other (single-layer two-floors (winding1), single-layer threefloors (winding2), and double layer (winding3)) and the same stator was performed for all. 
Constructions of stator and rotor of used motors were performed considering AGM 90S4 type $1.1 \mathrm{~kW}$ motor, $380 \mathrm{~V}$ star connection, $2.75 \mathrm{~A}, \cos \varphi=0.81,50 \mathrm{~Hz}, 3$-phase, and $1380 \mathrm{rpm}$.

A rotor's parameters for each phase basis referred to the stator measurements in experiments: $X_{2 \sigma}^{\prime}=$ $15.04 \Omega$ and $\mathrm{R}_{2}^{\prime}=8.818 \Omega$. Slip (s) was modified for testing no load ( 0.0013 for all windings), load ( 0.0873 for winding $1,0.0833$ for winding 2 , and 0.0913 for winding 3 ), and locked rotor ( 1 for all windings); and. $R_{1}$ and $X_{1 \sigma}$ values were those shown in Figure 3 (Kentli \& Temiz, 1999). The experimental setup is shown in Figure 4.

Figure 3: Stator winding effective ohmic resistance $\left(\mathrm{R}_{1}\right)$ and stator leakage flux reactance values $\left(\mathrm{X}_{1 \sigma}\right)$

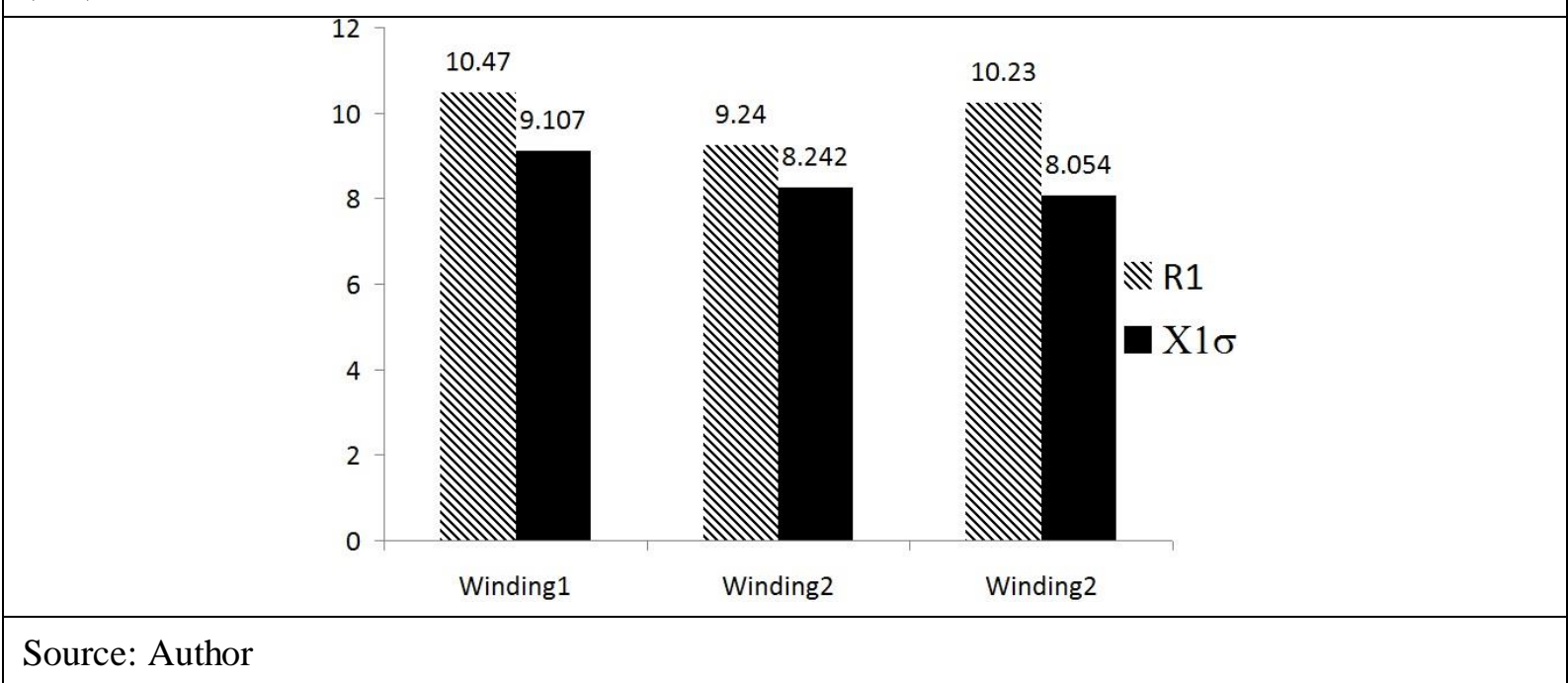

\section{Results}

The measured phase current $\left(\mathrm{I}_{1}\right)$ and calculated power are shown in Figures 5 and 6, respectively (Kentli \& Temiz, 1999). Calculated parameter values are tabulated in Table 1.

Figure 4: Experimental setup

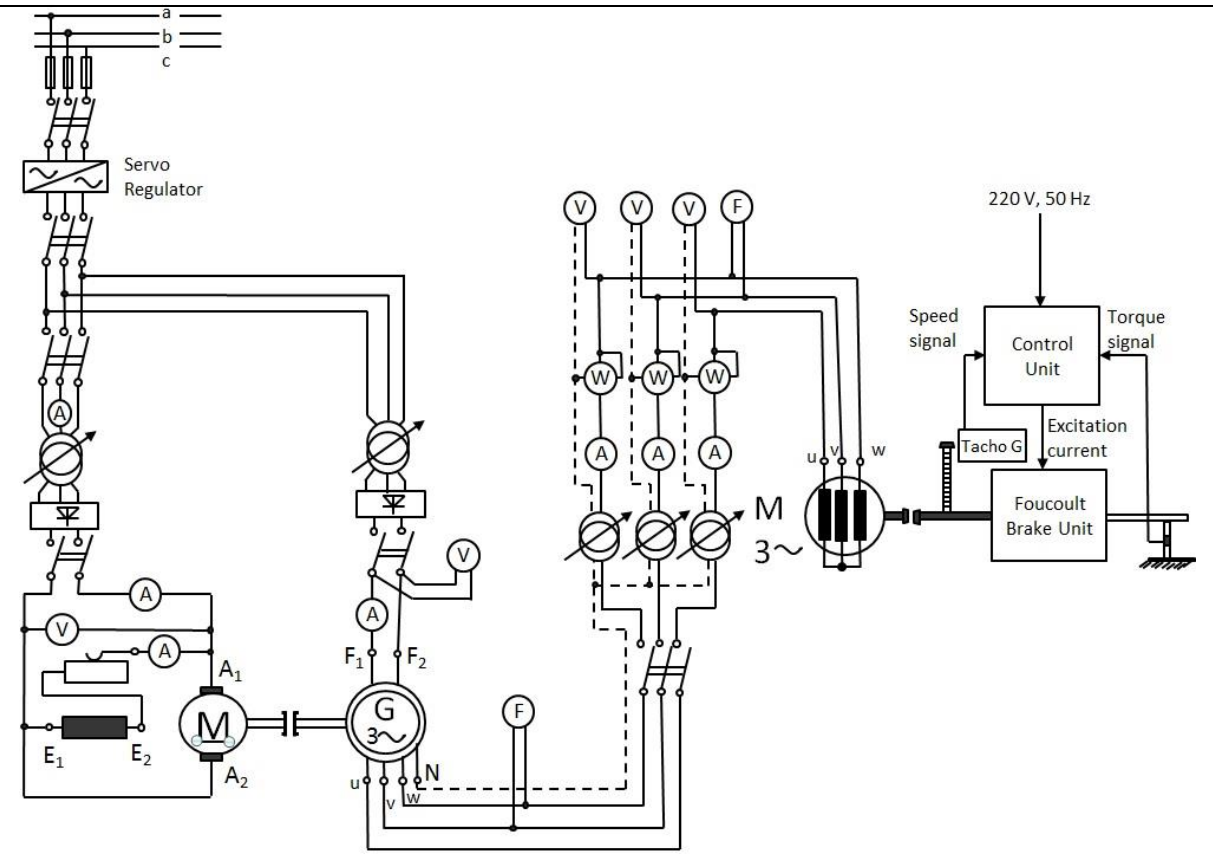

Source: Author 
Figure 5: $I_{1}(A)$ current values measured in different winding types.

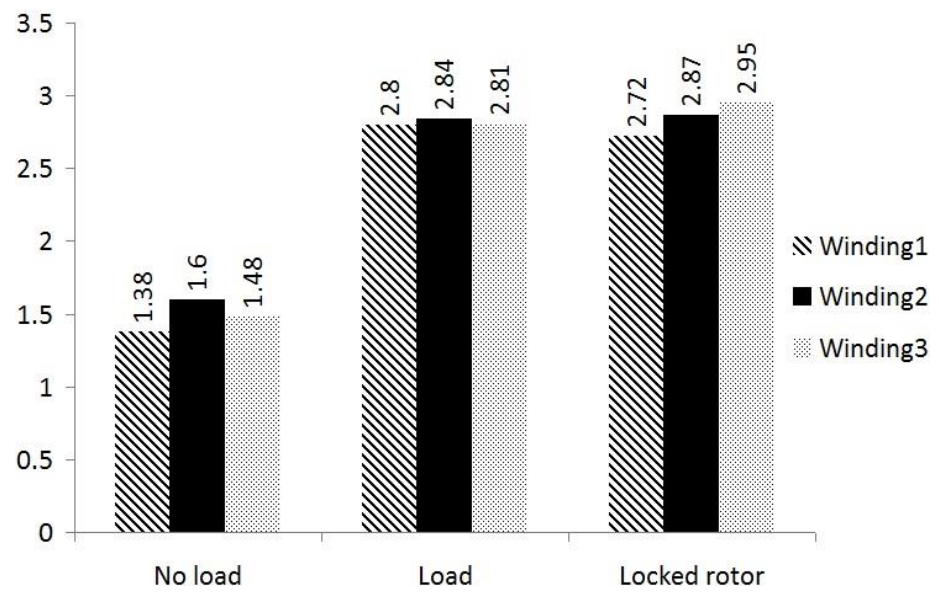

Source: Author

Figure 6: The power factor obtained from different winding types

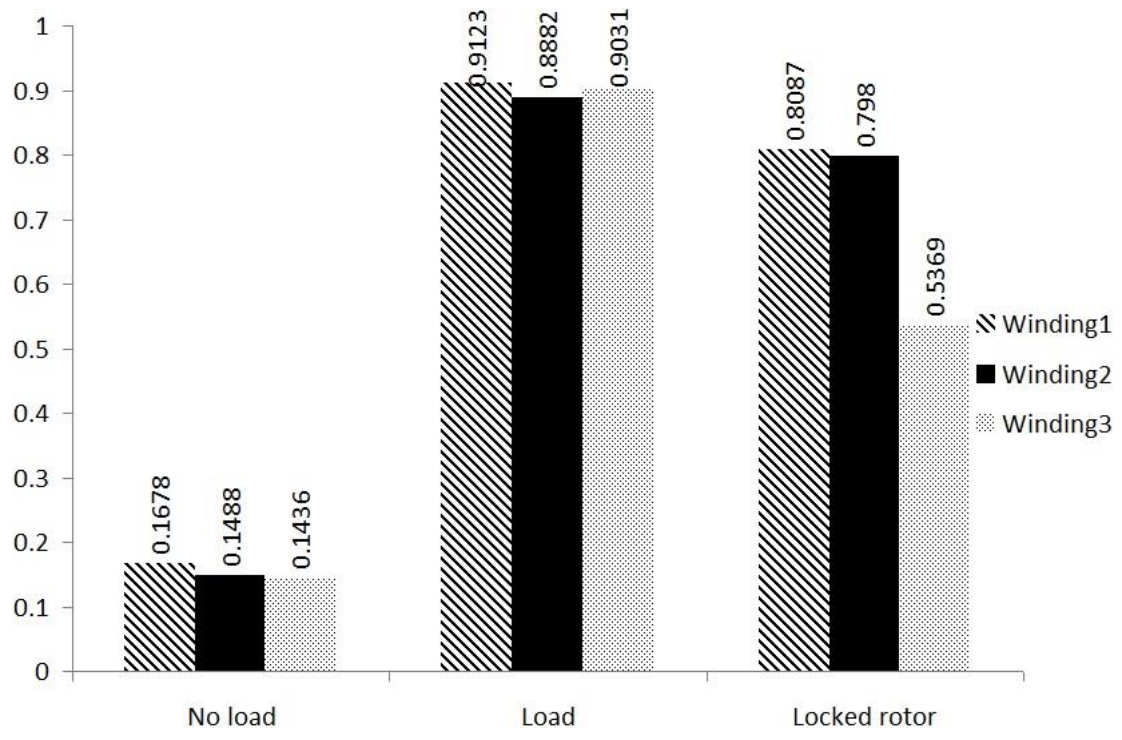

Source: Author

Table 1: Calculated impedance values and rates of iron loss resistance to magnetizing reactance

\begin{tabular}{|l|c|c|c|r|r|r|r|r|r|}
\hline & \multicolumn{3}{|c|}{ Single-layer two-floors } & \multicolumn{3}{c|}{ Single-layer three-floors } & \multicolumn{3}{|c|}{ Double layer } \\
\hline & $\begin{array}{c}\text { No } \\
\text { load }\end{array}$ & Load & $\begin{array}{c}\text { Locked } \\
\text { rotor }\end{array}$ & $\begin{array}{c}\text { No } \\
\text { load }\end{array}$ & Load & $\begin{array}{c}\text { Locked } \\
\text { rotor }\end{array}$ & $\begin{array}{c}\text { No } \\
\text { load }\end{array}$ & Load & $\begin{array}{c}\text { Locked } \\
\text { rotor }\end{array}$ \\
\hline $\mathbf{Z}_{\mathbf{1}}(\boldsymbol{\Omega})$ & 13.88 & 13.88 & 13.88 & 12.38 & 12.38 & 12.38 & 13.02 & 13.02 & 13.02 \\
& $\angle 41.0^{\circ}$ & $\angle 41.0^{\circ}$ & $\angle 41.0^{\circ}$ & $\angle 41.7^{\circ}$ & $\angle 41.7^{\circ}$ & $\angle 41.7^{\circ}$ & $\angle 38.2^{\circ}$ & $\angle 38.2^{\circ}$ & $\angle 38.2^{\circ}$ \\
\hline $\mathbf{Z}_{\mathbf{t}}(\boldsymbol{\Omega})$ & 159.42 & 78.57 & 25.74 & 137.50 & 77.47 & 24.40 & 148.65 & 78.30 & 23.73 \\
& $\angle 80.3^{\circ}$ & $\angle 24.2^{\circ}$ & $\angle 36.0^{\circ}$ & $\angle 81.4^{\circ}$ & $\angle 27.4^{\circ}$ & $\angle 37.1^{\circ}$ & $\angle 81.7^{\circ}$ & $\angle 25.4^{\circ}$ & $\angle 57.5^{\circ}$ \\
\hline $\mathbf{R}_{\mathbf{f e}} / \mathbf{X}_{\mathbf{m}}$ & 6.50 & 14.60 & 80.00 & 7.35 & 14.00 & 76.50 & 7.62 & 15.83 & 96.50 \\
\hline
\end{tabular}

Source: Author 


\section{Conclusion}

Experimental results show that changing winding types influences power and therefore the motor efficiency. No load tests displayed the highest power $(\cos \varphi)$ in the category of single-layer two-floor winding, and the lowest in that of double layer winding. Among tested winding types, single-layer two-floor produced the best power in all cases (load, no load, and locked rotor).

The no load tests showed the lowest current values occurred in single-layer two-floor winding and the highest in single-layer three-floor type. This shows that the highest total impedance value of equivalent circuit belongs to single-layer two-floor winding type and the lowest total impedance value of equivalent circuit value to single-layer three-floor type.

Also, equivalent circuit parameter values were calculated satisfactorily. The rate values of iron loss resistance to magnetizing reactance were computed and for every winding type this rate increased at load with different values for each winding type. The lowest rates were observed at no load and highest at locked rotor for each winding type.

\section{Acknowledgments}

This was supported by Marmara University Scientific Research Projects Committee (BAPKO).

\section{References}

Boglietti, A., Cavagnino, A., \& Lazzari, M. (2011). Computational algorithms for induction-motor equivalent circuit parameter determination - Part I: Resistances and leakage reactances. IEEE Transactions on Industrial Electronics, 58(9), 3723-3733. DOI: 10.1109/TIE.2010.2084974

Boglietti, A., Bojoi, R. I., Cavagnino, A., Guglielmi, P., \& Miotto, A. (2012). Analysis and modeling of rotor slot enclosure effects in high-speed induction motors. IEEE Transactions on Industry Applications, 48(4), 1279-1287. DOI: 10.1109/TIA.2012.2199270

Buksnaitis, J. (2010). Power Indexes of Induction Motors and Electromagnetic Efficiency their Windings. Elektronika ir Elektrotechnika, 4(100), 11-14.

Gastli, A. (1999). Identification of induction motor equivalent circuit parameters using the single-phase test. IEEE Transactions on Energy Conversion, 14(1), 51-56. DOI: 10.1109/60.749147

Hadziselimovic, M., Marcic, T., Stumberger, B., \& Zagradisnik, I. (2011). Winding type influence on efficiency of an induction motor. Przeglad Elektrotechniczny, 87(3), 61-64.

Kentli, F., \& Temiz, İ. (1999). Asenkron Motorlarda Stator Sargı Yapısındaki Değişikliğin Güç Katsayısına Etkisi, presented at 8th National Congress on Elektrical-Electronic-Computer Engineering Mühendisliği, Gaziantep, Türkiye, 1999.

Kral, C., Haumer, A., \& Grabner, C. (2010). Consistent Induction Motor Parameters for the Calculation of Partial Load Efficiencies by Means of an Advanced Simulation Model. Engineering Letters, 18(1), 28-40.

Ling, Z., Zhou, L., Guo, S., \& Zhang, Y. (2014). Equivalent circuit parameters calculation of induction motor by finite element analysis. IEEE Transactions on Magnetics, 50(2), 833-836. DOI: 10.1109/TMAG.2013.2282185

Phumiphak, T., \& Chat-Uthai, C. (2002). Estimation of induction motor parameters based on field test coupled with genetic algorithm, presented at IEEE International Conference on Power System Technology, Bangkok, Thailand, 2002. DOI: 10.1109/ICPST.2002.1047592

Sivaraju, S., \& Chandrasekaran, V. (2014). Optimum design of multiple winding induction motor. Journal of Theoretical \& Applied Information Technology, 65(2), 467-479.

Saravanan, M. C., Azarudeen, A. M., \& Selvakumar, S. (2012). Performance of three phase induction motor using modified stator winding. GJRE-F: Electrical and Electronic Engineering, 12(5), 1-5.

Zhang, L., Huang, Y., Dong, J., Guo, B., \& Zhou, T. (2014). Stator winding design of induction motors for high efficiency, presented at IEEE 17th International Conference on Electrical Machines and Systems, Nanjing, China, 2014. DOI: 10.1109/ICEMS.2014.7013451 